\title{
Risk Factors Associated with Peptic Ulcer Disease
}

\section{Gufran Kadhim, Hishamuddin Omar and Ahmad Ismail*}

Faculty of Science, Department of Biology, University Putra Malaysia, 43400 UPM Serdang, Selangor, Malaysia

\begin{abstract}
Background: Helicobacter pylori $(H$. pylori) infection is usually acquired in early childhood. $H$. pylori infection is associated with several upper gastrointestinal disorders. Since $H$. pylori affects about $50 \%$ of the population in their lifetime therefore there is a necessity to examine the extent of the disease and to study the risk factors associated with $H$. pylori infection. The purpose of this study is to evaluate the rate of $H$. pylori infection among the target population.

Methods: This study included one hundred seventy eight randomly selected participants by interview and questionnaire. The independent variables included in the questionnaire were: age, sex, weight, marital status, smoking, drink tea, drink coffee, type of drinking water during childhood and adulthood (filtered, unfiltered water). HpSAg test were used to detect antigen in stool specimen.

Results: In crude analysis, the infection risk was associated with type of drinking water during childhood with $\mathrm{P}$ value $=0.018$. Tea drinking seemed to be a protective factor against $H$. pylori infection

Conclusions: The independent variables were considered as risk factors with peptic ulcer disease. $H$. pylori infection appears to be multifactorial. The results of this work supported the hypothesis that $H$. pylori acquisition occurs early in childhood and persist throughout life.
\end{abstract}

Keywords: Peptic ulcer disease; H. pylori; HpSAg; Socioeconomic status; Childhood

\section{Introduction}

Peptic ulcer disease (PUD) results from an inequality of acid secretion and mucosal defenses that resist acid digestion. Moreover, studies have confirmed the strong relationship between gastric antral infection with $H$. pylori and peptic ulceration. More than $90 \%$ of patients with peptic ulcer disease are infected with $H$. pylori and eradication of this infection not only heals most simple ulcers but also significantly decreases the likelihood of recurrent ulceration [1,2].

The prevalence of $H$. pylori infection worldwide is nearly $50 \%$, it reaches as high as $80 \%-90 \%$ in developing countries, and about $35 \%$ $40 \%$ in the united states [3]. Half of the world's population is estimated to be infected with $\mathrm{H}$. pylori, which makes it as one of the most common bacterial pathogens in human [4]. Nearly $20 \%$ of persons infected with $H$. pylori develop related gastro duodenal disorders during their lifetime.

Several studies have been conducted in Iraq to evaluate the prevalence of $H$. pylori infection in peptic ulcer disease indicating in the range of $60 \%$ - 70\% [5]. In Egypt, the prevalence of $H$. pylori infection was $10 \%$ among children [6]. There was 9323 death due to gastric cancer between 1991- 2000 in Sweden [7]. The annual incidence of $H$. pylori infection is around $4 \%-15 \%$ in developing countries, compared with approximately $0.5 \%$ in industrialized countries [8]. Documented risk factors included low socioeconomic status, overcrowding, poor sanitation or hygiene, which normally associated with developing country [9]. Socioeconomic conditions in childhood, ethnicity and presence of dyspeptic were the factors significantly associated with the infection [10]. In simple analyses, prevalence was associated with increasing age, non- white skin level, big family size, low socioeconomic conditions in childhood, higher number of siblings, child attending to day-care centers, and presence of dyspeptic symptoms.

In Malaysia, the prevalence of $H$. pylori infection among patients diagnosed with peptic ulcer disease was low but ethnicity and smoking were significant factors associated with the infection [11].
The infection is more prevalent in lower socioeconomic groups with poor living standards, crowded living conditions [12], those with lower levels of education and poor hygiene [13]. The objective of this study is to determine the prevalence of $H$. pylori infection among patients diagnosed with peptic ulcer disease and its associated factors.

\section{Methods}

The appropriate permissions were taken from the upm student health center for sample collection, and consent was obtained from the patients to make the interview and the sample collection. Patients were informed about the aim of this study and an oral agreement was given by the patient before any sample collection or interview. Eligible participants with possible $H$. pylori infection were distinct as those patients independently assessed by their attending physician based on clinical symptoms (Destura et al., 2004). There was no specific age limitation for participant.

\section{Sample size}

Two hundred randomly selected eligible participants with suggested symptoms of peptic ulcer disease in Serdang Kuala Lumpur. Stool samples were collected from one hundred seventy eight responded for interview and questionnaire. The study population age ranged between 14-65 years. One hundred and fourteen are males and 64 females.

*Corresponding author: Ahmad Ismail, Faculty of Science, Department of Biology, University Putra Malaysia, 43400 Serdang, Selangor, Malaysia, E-mail: aismail@upm.edu.my

Received: December 20, 2014; Accepted: February 25, 2015; Published: March 02, 2015

Citation: Kadhim G, Omar H, Ismail A (2015) Risk Factors Associated with Peptic Ulcer Disease. J Bioengineer \& Biomedical Sci 5: 142. doi:10.4172/21559538.1000142

Copyright: $\odot 2015$ Kadhim G, et al. This is an open-access article distributed under the terms of the Creative Commons Attribution License, which permits unrestricted use, distribution, and reproduction in any medium, provided the original author and source are credited. 
Citation: Kadhim G, Omar H, Ismail A (2015) Risk Factors Associated with Peptic Ulcer Disease. J Bioengineer \& Biomedical Sci 5: 142. doi:10.4172/2155- 9538.1000142

Page 2 of 4

\section{Questionnaire}

An interview questionnaire was used to collect data from eligible patients. The independent variables included in the questionnaire were; age, sex, weight, marital status, smoking, drink tea, drink coffee, type of water drinking during childhood and adulthood (filtered, unfiltered water).

\section{Stool sample for antigen detection}

About $0.2 \mathrm{~g}$ of stool was collected into a sterile container. All stool samples were frozen at $-20^{\circ} \mathrm{C}$ until tested for $\mathrm{H}$. pylori antigen by HpSAg kit (DRG-Germany). Methods of analysis followed the manufacturer instruction.

\section{Calculation of result}

For qualitative reading: The test results were calculated by means of cut-off value determined from the OD450 $\mathrm{nm}$ value of the (CALO) and the OD450 $\mathrm{nm}$ of the CAL0.1 $\mu \mathrm{g} / \mathrm{ml}$ with the following formula: Cut-off $=($ CAL0 + CAL0.1 $) / 2$.

Analysis of data: Data generated from the study was tabulated as Microsoft Excel sheets and uploaded to Statistical Package for Social Sciences (SPSS version 11). Cross tabulation of variables were generated. Chi square was used to detect statistically significant correlation among variables.

\section{Results}

This study was conducted during the period from February 2014 to January 2015. During the study period, 178 patients with symptoms suggestive of peptic ulcer disease were interviewed and they answered several questions regarding personal information and their life style. Stool specimens were collected. Data obtained are organized as follows

\section{Personal variables}

Among the 178 subjects who completed data, the highest negative result was in age group 14-20yr (66.7\%) while the highest positive result was found in the age group 21-35yr (51.1\%). The highest positive result was in female and it constituted $53.1 \%$, while in male it was $45.6 \%$. There were no significant statistical results related to age or sex to be considered as a risk factor. The highest positive result was found in weight group $35-50 \mathrm{~kg}$ comprising $87.5 \%$ but the lowest results were in weight group $83-98 \mathrm{~kg}$. With regard to marital status, there were no significant differences ( $\mathrm{p}$ value $=0.440$ ). Both married and single subjects were nearly equally at risk (Table 1 ).

\section{Life style variables}

Life style differs from region to region and depends on many factors such as socioeconomic factors, geographical distribution and religion. Such variations are used in justifying conflicting results obtained by different investigators. As shown in Table 2, there is no significant difference ( $\mathrm{p}$ value $=0.507$ ) between smokers and non-smokers with respect to $H$. pylori infection. The percentage of positive results for smokers and non-smokers were $46.9 \%$ and $49.1 \%$ respectively. Even the number of cigarettes seems not to affect or increase the probability of infection. There is a statistically significant differences among subjects who drink tea and those who do not with $\mathrm{P}$ value $=0.045$. Subjects who drink coffee are less likely to develop $H$. pylori infection (41.0\%) as compared to those who don't drink coffee (54.0\%).

However, the difference is not statistically significant. With respect to the number of cups per day, lower percentage of $H$. pylori

\begin{tabular}{|c|c|c|c|c|c|c|}
\hline \multirow[t]{3}{*}{ Variable } & & \multicolumn{4}{|c|}{ H. pylori infection } & \multirow{3}{*}{$\begin{array}{c}\boldsymbol{P} \\
\text { value }\end{array}$} \\
\hline & & \multicolumn{2}{|c|}{ Negative } & \multicolumn{2}{|c|}{ Positive } & \\
\hline & & No & $\%$ & No & $\%$ & \\
\hline & $14-20 y$ & 8 & 66.7 & 4 & 33.3 & \\
\hline & $21-35 y$ & 46 & 48.9 & 48 & 51.1 & \\
\hline \multirow[t]{6}{*}{ Age } & $36-50 y$ & 22 & 50.0 & 22 & 50.0 & 0.832 \\
\hline & $>51 \mathrm{y}$ & 16 & 57.1 & 12 & 42.9 & \\
\hline & Male & 62 & 54.4 & 52 & 45.6 & \\
\hline & Female & 30 & 46.9 & 34 & 53.1 & 0.323 \\
\hline & $35-50$ & 2 & 12.5 & 14 & 87.5 & \\
\hline & $51-66$ & 46 & 57.5 & 34 & 42.5 & 0.125 \\
\hline \multirow[t]{3}{*}{ Weight } & $67-82$ & 40 & 52.6 & 36 & 47.4 & \\
\hline & $83-98$ & 4 & 66.7 & 2 & 33.3 & \\
\hline & Married & 76 & 50.7 & 74 & 49.3 & \\
\hline Marital status & Single & 16 & 57.1 & 12 & 42.9 & 0.440 \\
\hline
\end{tabular}

Table 1: Personal factors: Age, sex, weight, marital status with respect to $H$. pylor prevalence.

\begin{tabular}{|c|c|c|c|c|c|c|}
\hline & & \multicolumn{4}{|c|}{ H. pylori infection } & \multirow{3}{*}{$\begin{array}{c}\boldsymbol{P} \\
\text { value }\end{array}$} \\
\hline \multicolumn{2}{|l|}{ Variable } & \multicolumn{2}{|c|}{ Negative } & \multicolumn{2}{|c|}{ Positive } & \\
\hline & & No & $\%$ & No & $\%$ & \\
\hline \multirow[t]{2}{*}{ Smoking } & No & 58 & 50.9 & 56 & 49.1 & 0.507 \\
\hline & Yes & 34 & 53.1 & 30 & 46.9 & \\
\hline \multirow[t]{2}{*}{ If smoking } & $1-20$ & 26 & 48.1 & 28 & 51.9 & 0.208 \\
\hline & $>20$ & 8 & 80.0 & 2 & 20.0 & \\
\hline \multirow[t]{2}{*}{ Drink tea } & No & 2 & 14.3 & 12 & 85.7 & 0.045 \\
\hline & Yes & 90 & 54.9 & 74 & 45.1 & \\
\hline \multirow{2}{*}{$\begin{array}{l}\text { How many cups per } \\
\text { day }\end{array}$} & $1-5$ & 40 & 55.6 & 32 & 44.4 & 0.194 \\
\hline & $>5$ & 6 & 100 & - & - & \\
\hline \multirow[t]{2}{*}{ Drink of coffee } & No & 46 & 46.0 & 54 & 54.0 & 0.158 \\
\hline & Yes & 46 & 59.0 & 32 & 41.0 & \\
\hline \multirow{2}{*}{$\begin{array}{l}\text { How many cups per } \\
\text { day }\end{array}$} & $1-5$ & 72 & 54.5 & 60 & 45.5 & 0.564 \\
\hline & $>5$ & 18 & 56.2 & 14 & 43.8 & \\
\hline \multirow[t]{2}{*}{$\begin{array}{l}\text { Type of drinking water } \\
\text { during childhood }\end{array}$} & $\begin{array}{l}\text { Unfiltered } \\
\text { water }\end{array}$ & 72 & 46.8 & 82 & 53.2 & 0.018 \\
\hline & Filtered water & 20 & 83.3 & 4 & 16.7 & \\
\hline $\begin{array}{c}\text { Type of drinking water } \\
\text { during }\end{array}$ & $\begin{array}{l}\text { Unfiltered } \\
\text { water }\end{array}$ & 16 & 50 & 16 & 50 & 0.548 \\
\hline Adulthood & Filtered water & 74 & 52.1 & 68 & 47.9 & \\
\hline
\end{tabular}

$P$ value $<0.05$ significant

Table 2: Life style variables.

infection was detected among those who consume more than 5 cups per day ( $p$ value $=0.194$ ). From statistical analysis of data, the type of water drunk during childhood could be considered as a risk factor with $\mathrm{P}$ value $=0.018$. As shown in Table 2, the positive results were high among subjects who drunk unfiltered water during childhood $53.2 \%$ while subjects who drunk filtered water during childhood have $16.7 \%$ positive results. However, the type of drinking water during adulthood did not affect the result of $H$. pylori infection (Table 2) [14].

\section{Discussion}

The data of this study suggested that type of drinking water at early age, and non-tea drinking is more susceptible to $H$. pylori infection. This study established that the highest positive results were in the age group of 21-35 yr. (51.1\%). However, there were no statistically significant differences between all age groups. This result does not agree with similar studies in developed countries which indicated that the infection begin in younger age and increasing yearly with age. This 
is probably due to limited numbers of participant of old age. A study in Brazil, where the infection rate was of $84.7 \%$ in subjects 18 to 30 years of age, increasing to $92 \%$ in subjects $46-60$ years old, while in subject above 60 years old, the prevalence decreased slightly. As a whole, the prevalence of infection did not increase significantly $(\mathrm{P}=0.147)$ with age. This has been explained as due to a reduction in the specific serological response among older individuals and/or to a decreased number of microorganisms as a consequence of gastric atrophy [15]. There is no significant difference in the overall prevalence of $H$. pylori infection between males and females as shown in Table 2. This finding is in agreement with study done by Rodrigues et al. in Brazil, which involving two hundred and four participants; 49 males and 155 females, with ages ranging from 18 to 80 years. One hundred sixty five of two hundred and four participants $(80 \%)$ were $\mathrm{H}$. pylori positive, with no significant gender differences $(\mathrm{P}=0.49)$.

The highest positive result was in weight group $35-50 \mathrm{Kg}(87.5 \%)$ and this percentage did not increase with increasing weight as shown in Table 2. This may be explained the fact that malnutrition could lower immunity and therefore increase the susceptibility of those patients to be infected with $H$. pylori organism. A study in UK (2005) demonstrated a relation between $H$. pylori infection and weight loss. Ninety seven patients were $H$. pylori positive. Their results suggest that children with dyspepsia and $H$. pylori infection are shorter and lighter compared to children without the infection. It is possible that H. pylori infection may have some detrimental effect on growth, especially during the pubertal growth spurt [16]. Although a slightly higher percentage of $H$. pylori infection was showed among married than single subjects. But the increase was not statistically significant. While a study in Libya by Bakka and Salih showed a higher prevalence of $H$. pylori in married subjects $(84 \%)$ in comparison to single subjects (68\%) [17]. There were no statistical differences between smokers and non-smokers [30 (46.9\%), 56 (49.1\%) respectively) with respect to $H$. pylori infection (Table 2). A striking observation smoking of more than 20 cigarettes reduced the rate of $H$. pylori. There are reasons why smoking might have slight effect on, or even increase, the hostility of the gastric environment to $H$. pylori. The acid gastric $\mathrm{pH}$ avoids most organisms from thriving or even surviving in the stomach. H. pylori, on the other hand, has an electropositive internal milieu; twice the number of basic amino acids, arginine and lysine, as Haemophilus influenza and Escherichia coli; and powerful urease activity, with the ability to produce both ammonia and factors that inhibit parietal cell acid production [18]. These characteristics make survival of $H$. pylori in the stomach less influenced by the reduction in $\mathrm{pH}$ which may attend with smoking [19]. As shown in Table 2, a significant finding of this study is that tea consumption is a protective factor. Only $45.1 \%$ of those who drinks tea were infected, a very much higher percentage was observed among those who do not drink tea (85.7\%). This result is supported by a Japanese study (1999) on the benefits of tea. New studies have offered data that show a variety of biological activities of tea catechins, compounds which constitute around 15\% (dry weight) of tea. They studied the antibacterial activity of catechins against $H$. pylori in vitro and in vivo. Effect of these compounds, tea examined on the gastric mucosal injury induced by this organism in Mongolian gerbils. $H$. pylori were eradicated in around $10 \%$ of the gerbils in each of the catechin. Catechins might damage the membrane of $H$. pylori. But, the exact mechanism is still unknown. Moreover, catechins inhibit the urease activity and motility of $H$. pylori [20]. There was no statistically significant difference between those who drink or don't drink coffee. Actually a little bit lower percentage of positive.

H. pylori was found in those who drink coffee (41.0\%) than those who do not $(54.0 \%)$. The number of cups consumed per day seems to affect the outcome of $H$. pylori infection. Among those who drink more than 5 cups, none were positive. A study in Germany in 1997 on 447 patients with an overall prevalence of $21 \%$, coffee consumption showed a positive dose-response relation with active infection. The positive relation between coffee consumption and $H$. pylori infection recognized in that study is consistent with results from a cohort study among epidemiologists in which the risk of seroconversion (change from negative to positive results for antibodies to $H$. pylori in serum) was 4.6 times higher among those who drank more than 2 cups of caffeinated drinks a day than among the others. The mechanisms underlying this association require extra research [21].

Type of water drunk during childhood is considered as a detrimental factor with a statistical significant results $(\mathrm{P}$ value $=0.018) . H$. pylori infection rate was high in subjects who consumed unfiltered water during childhood (53.2\%) in comparison with subjects who consumed filtered water during childhood (16.7\%). In childhood, or young age, the immune system is developing. Exposing to contaminated water might compromise the immune system leading to high prevalence [22].

The type of drinking water during adulthood is not considered as a risk factor. Both unfiltered water and filtered water consumers showed similar infection rates $(50.0 \%)$ and (47.9\%) respectively.

\section{Conclusions}

The factors such as age, sex, weight, marital status, smoking, coffee consumption could not be considered as a risk factor of $H$. pylori infection as confirmed by the results of this study. The statistical analysis of data attained from this study showed a significant protective property of tea against $H$. pylori infection with a significant $P$ value. Our results support the hypothesis that $H$. pylori infection in developing countries is mainly acquired during childhood.

\section{References}

1. Higham J, Kang JY, Majeed A (2002) Recent trends in admissions and mortality due to peptic ulcer in England: increasing frequency of haemorrhage among older subjects. Gut 50: 460-464.

2. Svanes C, Salvesen H, Bjerke Larssen T, Svanes K, Soreide O (1990) Trends in and value and consequences of radiologic imaging of perforated gastroduodenal ulcer. A 50-year experience. Scand J Gastroenterol 25: 257262.

3. Lacy B, Semore J (2001) Helicobacter pylori: ulcers and more: the beginning of an era. J Nutr 131: 89-93.

4. Torres J, Perez-Perez G, Goodman K, Atherton J, Gold B, et al. (2000) A comprehensive review of the natural history of Helicobacter pylori infection in children. Arch Med Res 31: 431-469.

5. Al-Sari ZWA (2003) Extraction and purification of urease from a local isolate of Helicobacter pylori as a specific antigen and using it in enzyme linked immunosorbent assay (ELISA) [MSC thesis]. Basra, Iraq, College of Science Basrah University.

6. Abdollah B, Robert W, Remon A, Yongdai K, Malla R., et al. (2000) Seroepidemiology of Helicobacter pylori infection in a population of Egyptian children. Int J Epidemiol 29: 928-932.

7. Sonnenberg A (2011) Time trends of mortality from gastric cancer in Europe. Dig Dis Sci 56: 1112-1118.

8. Gold B (2001) Helicobacter pylori infection in children. Curr Probl Pediatr Adolesc Health Care 3: 247-266.

9. Brown $L$ (2000) Helicobacter pylori: epidemiology and routes of transmission Epidemiol Rev 22: 83-97.

10. Ina S, Jose B, Ari S, Neiva C, Camila S, et al. (2005) Prevalence of Helicobacter pylori infection and associated factors among adults in Southern Brazil: a population-based cross-sectional Study. BMC Public Health 5: 118. 
Citation: Kadhim G, Omar H, Ismail A (2015) Risk Factors Associated with Peptic Ulcer Disease. J Bioengineer \& Biomedical Sci 5: 142. doi:10.4172/2155- 9538.1000142

Page 4 of 4

11. Pillay KVK, Htun M, Naing NN, Norsa'adah B (2007) Helicobacter Pylori Infection in Peptic ulcer disease: the importance of smoking and ethnicity. Southeast Asian J. Trop Med Public Health 38: 1102-1110.

12. Goodman K, Correa P (2000) Transmission of Helicobacter pylori among siblings. Lancet 355: 358-362.

13. Graham D, Karen G, Taufer M, Mohandas K (1995) Evidence for high prevalence of Helicobacter pylori infection among children of developing countries. Aliment Pharmacol Ther 102: 110-111.

14. Destura R, Labio E, Barrett L, Alcantara C, Gloria V, et al. (2004) Laboratory diagnosis and susceptibility profile of Helicobacter pylori infection 104 in the Philippines. Annals of Clinical Microbiology and Antimicrobials 16: 25.

15. Rodrigues $M$, Queiroz D, Rodrigues R, Rocha A, Braga Neto $M$, et al. (2005) Helicobacter pylori infection in adults from a poor urban community in northeastern Brazil: demographic, lifestyle and environmental factors. Braz J Infect Dis 9: 405-410.

16. Malfertheiner P, Peitz $U$ (2005) The interplay between Helicobacter pylori, gastro- oesophageal reflux disease, and intestinal metaplasia. Gut 54: 13-20.
17. Bakka A, Salih B (2002) Prevalence of Helicobacter pylori infection in asymptomatic subjects in Libya. Diagn Microbiol Infect Dis 43: 265-268.

18. Tomb J, White O, Kerlavage A, Clayton R, Sutton G, et al. (1997) The complete genome sequence of the gastric pathogen Helicobacter pylori. Nature 388 539-547.

19. Endoh K, Leung F (1994) Effects of smoking and nicotine on the gastric mucosa: A review of clinical and experimental evidence. Gastroenterol 107 864-878

20. Mabe K, Yamada M, Oguni I, Takahashi T (1999) In Vitro and In Vivo Activities of Tea Catechins against Helicobacter pylori. Antimicrob Agent and Chemother 43: 1788-1791.

21. Brenner H, Rothenbacher D, Bode G, Adler G (1997) Relation of smoking and alcohol and coffee consumption to active Helicobacter pylori infection: cross sectional study. BM J 315: 1489-1492.

22. http://www.chemtox.com/immunesystem/water/drinking_water. 